\title{
Burnout and job satisfaction of healthcare workers in Slovenian nursing homes in rural areas during the COVID-19 pandemic
}

\author{
Ljiljana Leskovic ${ }^{1, A-B, F \oplus}$, Karmen Erjavec ${ }^{1, A, C-D \oplus}$, Robert Leskovar ${ }^{2, A, F \oplus}$, Goran Vukovič2,A,F \\ ${ }^{1}$ University of Novo Mesto Faculty of Health Sciences, Slovenia \\ ${ }^{2}$ Faculty of Organizational Sciences, University of Maribor, Slovenia \\ A - Research concept and design, B - Collection and/or assembly of data, C - Data analysis and interpretation, \\ $D$ - Writing the article, $E$ - Critical revision of the article, $F$ - Final approval of article
}

Leskovic L, Erjavec K, Leskovar R, Vukovič G. Burnout and job satisfaction of healthcare workers in Slovenian nursing homes in rural areas during the COVID-19 pandemic. Ann Agric Environ Med. 2020; 27(4): 664-671. doi: 10.26444/aaem/128236

\begin{abstract}
Introduction and objective. Since there is no study on burnout and job satisfaction in Slovenian nursing homes during the COVID-19 pandemic, this study aims to analyse job satisfaction and burnout levels of healthcare professionals working in Slovenian nursing homes in rural areas during the COVID-19 pandemic, and make a comparison with the results of the same services in 2013.

Materials and method. The study is based on a cross-organisational and descriptive quantitative study conducted in spring $2013(n=556)$ and spring 2020 at the peak of the pandemic in Eastern Europe $(n=781)$ to identify the relationships and the changes in the satisfaction and burnout levels of healthcare professionals working in Slovenian nursing homes in rural areas, and on a qualitative study conducted in 2020, to identify in-depth relationships and changes in both studies during the COVID-19 pandemic.

Results. An increase in burnout syndromes between 2013 - 2020 was observed. The respondents experienced intensified emotional exhaustion and lack of personal accomplishment during the COVID-19 pandemic; however, depersonalisation did not differ statistically over the years. During the pandemic crisis, healthcare workers were less satisfied with their job than in spring 2013. Their job satisfaction was related to satisfaction with the work of nursing homes and with the work of state institutions and politicians who directly affected their working conditions and recognition in society.

Conclusions. The COVID-19 pandemic significantly exacerbated already existing burnout syndromes of nursing homes healthcare workers in Slovenian rural areas. Job satisfaction proved to be a relevant predictor of burnout syndrome. A negative correlation was observed between job satisfaction in 2020 and emotional exhaustion and personal accomplishment in 2013 and 2020.
\end{abstract}

Key words:

job satisfaction, professional burnout, healthcare workers, nursing homes, COVID-19 pandemic

\section{INTRODUCTION}

Nursing is a difficult and stressful job, widely considered to be one of the most stressful professions and associated with a high staff turnover, absenteeism, and a high degree of burnout [1]. Nurses and other healthcare professionals working in nursing homes report higher rates of burnout than those employed in any other healthcare organisation [1]. Studies from various countries in the developed world have shown that $30 \%-50 \%$ or even more healthcare workers in nursing homes exhibited burnout $[2,3,4,5]$, which poses a significant threat to patient safety and the quality of healthcare $[6,7,8,9]$.

The COVID-19 pandemic has raised concerns about the well-being and increased burnout of healthcare workers in nursing homes $[10,11]$. The disease has disproportionately affected nursing homes, and has been fatal particularly for their residents/patients, predominantly older adults [11]. In Slovenia, and other Central and Eastern European countries, as well as many other countries worldwide, nursing homes as primarily social institutions have been transformed into

Address for correspondence: Ljiljana Leskovic, University of Novo Mesto Faculty of Health Sciences, Na Loko 2,8000, Novo Mesto, Slovenia

E-mail: ljiljana.leskovic@uni-nm.si

Received: 04.09.2020; accepted: 07.10.2020; first published: 30.10 .2020 hospitals for elderly patients with the COVID-19 [11]. Some studies have reported that the COVID-19 pandemic could have exacerbated an already existing problem for nursing homes healthcare, such as high workload, high acuity of patients, and little time to complete a task, that precipitate burnout $[8,9,10,11]$. It is therefore important to study burnout syndromes during crises such as the COVID-19 pandemic, which could allow for timely action to prevent excessive burnout among healthcare professionals.

A well-known definition of burnout syndrome comes from Maslach [12] as an individual response associated with work-related stress over a long period of time that can affect job satisfaction, productivity, performance, turnover and well-being of both the healthcare professional and patient or resident. The three key dimensions of this response are 1) emotional exhaustion (EE) of the individual due to the loss of emotional resources and emotional/copy energy; 2) depersonalisation (DP) of the individual's detachment (including emotional detachment) from the patient or resident, as well as negative attitudes towards and lack of compassion for the patient or resident; 3) reduced personal accomplishment (PA), which includes the individual's negative feelings about the work and the perception of competence [13]. Burnout differs from psychological conditions with 
similar symptoms precisely in the interaction of these three dimensions [13]. In 2019, the World Health Organization classified burnout in the workplace as an occupational phenomenon based on three factors: 1) feelings of energy depletion or exhaustion; 2) increased mental distance from one's job, or feelings of negativism or cynicism related to one's job; 3) reduced professional efficacy [14].

Harrad and Sulla's review of the literature from 2000 2018 on factors associated with and the impact of burnout in nursing home care workers for the elderly shows that the factors related to burnout (depersonalization, emotional exhaustion and personal accomplishment) of different groups of workers (nurses, nurse assistants and nurse aides) could generally be classified as both organisationally and personally related [1]. Cooper et al. examined the literature up to August 2013 on factors that influence burnout in health care aides working in nursing homes, and showed that the factors associated with burnout in nurse assistants are similar to those reported among nurses, namely, many of the organizational factors (work environment, workload and facility) significantly precipitate burnout (emotional exhaustion, depersonalization, and personal accomplishment). Both literature reviews argued that sociodemographic variables had no significant effect on burnout dimensions $[1,15]$.

A meta-analysis of burnout shows that job satisfaction is negatively related to all three dimensions of burnout [16]. Based on management literature, job satisfaction dictates employee performance, which is directly associated with organization's performance [17]. The majority of studies on job satisfaction based on Herzberg and Mausner's motivator-hygiene theory [18] arguing intrinsic factors, also called also 'motivators' (e.g. challenging work, recognition for one's achievement, responsibility, opportunity to do something meaningful, involvement in decision-making, sense of importance in an organization) that give positive satisfaction arising from intrinsic conditions of the job itself, such as recognition, achievement, or personal growth and extrinsic factors, also called 'hygiene factors' (e.g. status, job security, salary, fringe benefits, work conditions, good pay, paid insurance, vacations), resulted in dissatisfaction. A Scandinavian study shows that job satisfaction while working in nursing homes has been identified as playing a significant role in staff intentions to continue working in nursing homes [19]. Annual income and household economic-well-being had a positive association with job satisfaction among healthcare workers in nursing homes [20]. Many studies have shown a negative relationship between job satisfaction and the burnout syndrome of nurses and doctors in a hospital environment from two perspectives: causes and consequences [20,21]. For example, a Turkish study on 250 emergency department professionals in two hospitals found out that a significant relationship exists between burnout and job satisfaction: emotional exhaustion was a significant predictor of all three dimensions of job satisfaction, while depersonalization had no significant effect on job satisfaction [20]. Moreover, gender, age, education and marital status had no significant effect on any form of satisfaction [20]. FontovaAlmató et al. [22] in 2018 observed an inverse relationship between depersonalisation and overall satisfaction in the analysis of satisfaction and burnout in the emergency department of a Spanish hospital, the results of which were compared with the results of the same service during the economic recession in 2012 [21]. On the other hand, some studies have shown exactly the opposite, that job satisfaction is a predictor of burnout [23]. Further research is needed to explore and explain the perspective of relationships between job satisfaction and burnout by using different approaches.

Burnout and job satisfaction were investigated among health professionals in the hospital environment with quantitative methods. There is a lack of research about the relationship between burnout and job satisfaction in nursing homes during the COVID-19 pandemic using a combination of methods. There is a particular research gap in the studies from Central and Eastern European countries, such as Slovenia, with $20 \%$ of the population over 65 and a poorlydeveloped long-term care system based only on informal care and nursing homes. Due to the lack of homes providing palliative care, nursing homes have increasingly taken over the healthcare function and become a kind of palliative hospital [23]. Employees in Slovenian private and public nursing homes report a heavy workload and low salary due to an inadequate regulation of healthcare professions, health care of residents who are mostly 'old-old' patients (average age of residents is 86 years) with many chronic diseases. This leads to great difficulties in recruiting and retaining staff [3].

\section{OBJECTIVE}

This study aimed to analyse job satisfaction and the burnout levels of healthcare professionals working in Slovenian nursing homes in rural areas during the COVID-19 pandemic, using quantitative and qualitative methods to obtain generalised and in-depth results. It was hypothesised that the job satisfaction and burnout levels of the healthcare professionals concerned are related and influenced by the pandemic. The study contributes to the scientific knowledge of the relationship between job satisfaction and burnout syndrome in healthcare professionals of nursing homes, and attempts to discover how workers are affected by occupational changes during a pandemic crisis.

\section{MATERIALS AND METHOD}

The cross-sectional and descriptive quantitative study was conducted in spring 2013 and spring 2020 to identify the relationships and their changes in the satisfaction and burnout levels of healthcare professionals working in Slovenian nursing homes in rural areas, and on the qualitative study conducted in 2020 to identify in-depth relations and changes in both studies during the COVID-19 pandemic.

Quantitative approach. For the purposes of the study, questionnaire were sent by regular post and e-mail to all private and public Slovenian nursing homes in rural areas $(\mathrm{N}=86)$ in 2013 (1 March - 30 April 2013) and in spring 2020 (30 March - 20 April 2020) at the peak of the pandemic in Eastern Europe $(\mathrm{N}=98)$. Healthcare managers in the nursing homes were informed about the study and requested to distribute the questionnaire or provide a link to the online survey to employed nurses, nursing assistants and nurse aides. Both methods were used to obtain data, as some potential respondents also insisted on completing a paper or online survey. In 2013, most respondents filled out the 
paper-based questionnaire; in 2020, most of them by the online questionnaire. In 2013, 556 respondents and in 2020, 781 respondents filled in the questionnaire completely (Tab. 1). 328 respondents completed both questionnaires. The response rate was higher in 2020 (24\%) than in 2013 (17\%).

The study protocol was reviewed and approved by the Ethical Committee of Human Research at the Faculty of Health Sciences, University of Novo Mesto, working within the Committee for Research (Approval No. 128). The Helsinki Declaration of the World Medical Association on the ethical principles for medical research on humans was respected.

Table 1. Socio-demographic characteristics of the sample in $2013(n=556)$ and $2020(n=781)$

\begin{tabular}{|c|c|c|c|c|}
\hline \multicolumn{2}{|c|}{ Socio-demographic factors } & \multirow{2}{*}{$\frac{2013 \text { n (\%) }}{33(5.7 \%)}$} & \multirow{3}{*}{$\begin{array}{c}2020 \text { n (\%) } \\
34(4.3 \%) \\
744(95.7 \%)\end{array}$} & \multirow{3}{*}{$\frac{p \text {-value }}{0.001}$} \\
\hline Gender & Male & & & \\
\hline & Female & $523(94.3 \%)$ & & \\
\hline Age $(\bar{X}, S D)$ & & $42.1(8.9)$ & $40.8(9.6)$ & \\
\hline \multirow{3}{*}{ Education } & Secondary school or less & $463(83.3 \%)$ & $636(81.5 \%)$ & \\
\hline & Bachelor's degree & $79(14.2 \%)$ & $128(16.4 \%)$ & 0.040 \\
\hline & Master's degree & $14(2.5 \%)$ & $17(2.1 \%)$ & \\
\hline \multirow{3}{*}{ Position } & Nurse & $70(12.6 \%)$ & $109(14.2 \%)$ & \\
\hline & Nursing assistant & $202(36.4 \%)$ & $298(38.1 \%)$ & 0.011 \\
\hline & Nurse aide & 284 (51.0\%) & 483 (47.7\%) & \\
\hline
\end{tabular}

The 2013 and 2020 versions of the questionnaire consisted of three parts and was partly tested in a doctoral dissertation [24]. The first part addressed the burnout syndrome by using the Maslach Burnout Inventory (MBI), which consisted of 22 items covering three aspects of burnout - nine items on emotional exhaustion (EE), five items on depersonalisation (D) and eight items on personal accomplishment (PA) scored on a Likert type scale [25]. The MBI shows high consistency and reliability, which is from $70 \%-95 \%$.

The second part dealt with job satisfaction using the short form of the MSQ validated in the Slovenian language (20 items from three dimensions with a Likert scale). Intrinsic satisfaction included factors of personal activities: personal feelings of freedom and independence, attitudes towards change, authority and responsibility and personal social status, moral values, recognition, skills, creativity and success. Extrinsic satisfaction included factors related to career opportunities, company policies and practices, colleagues, working conditions, insurance coverage, wages, human relations and leadership or management techniques. Overall satisfaction comprised two points on general satisfaction [25]. The MSQ showed a high consistency and reliability $-87 \%-88 \%$. In the third part, questions about the level of education, age, gender and positions were assessed.

Statistical analysis. Mann-Whitney U test, Spearman's Rho test and Kruskal-Wallis U test for comparing quantitative and categorical variables were used. A linear regression model was created to study the factors associated with the overall satisfaction of healthcare workers in both analysed years, adjusted for age and the dimensions of burnout syndromes. A comparative analysis of the results of the same questionnaire from 2013 was carried out. The data was analysed using SPSS 24.0.

Qualitative approach. In the second part of the study, in April 2020, in-depth semi-structured individual interviews were conducted by telephone to identify clear, accurate and inclusive opinions, based on personal experience on occupational changes during the pandemic crisis regarding job satisfaction and burnout.

Respondents, collection of data and questions. Since an attempt was being made to discover personal experiences in occupational changes during the pandemic crisis regarding job satisfaction and burnout, the snowball sampling method for recruitment of these respondents was used. The first group of respondents were contacted by project members through professional contacts. In turn, they recruited other respondents from among their colleagues. The respondents had more than two years' experience as nurses $(n=6)$, nurse assistants $(n=6)$ and nurse aides $(n=6)$ in public $(n=12)$ and private $(n=6)$ nursing homes in different rural parts of Slovenia. The nurses $(n=18)$ were of different genders, ages and positions.

Each interview included the following thematic questions: 'Can you describe your experience of burnout during the COVID-19 pandemic?' 'What is your job satisfaction during the COVID-19 pandemic?' 'Can you describe any changes during the COVID-19 pandemic regarding your job satisfaction and burnout?' The interviews were held by telephone due to the measure of social distancing, and lasted from 45-90 minutes, until a conceptual saturation was achieved. The interviews were recorded after the respondents had given their consent, transcribed and analysed by different researchers.

Analysis. In the analysis, the process of inductive analysis was followed in which themes emerged in the course of research. In a first step, the transcribed texts were generally read several times and descriptive comments made on the content. A second reading was carried out to code the data, i.e. to highlight phrases or sentences and add shorthand or codes to describe their content. Patterns were then identified from among the codes and combined with similar codes into an abstract single theme. The themes were reviewed by returning to the texts and checking whether the themes represented the content of the texts, and differentiated by age, gender and position. This step showed that there were no key differences in terms of subjects 'characteristics. Indexing, comprising sifting of the data, highlighting and sorting-out quotes and comparisons both within and between cases, were followed. Charting involved lifting the quotes from their original context and re-arranging them under the newly-developed appropriate thematic content. Mapping and interpretation of the analysis of individual quotes and construction of the relationship between quotes and links between the data as a whole, were carried out at the end [26]. Names and details have been withheld to protect the anonymity of the interviewees.

\section{RESULTS}

Quantitative analysis. Mann-Whitney U test was used to compare the burnout scores of healthcare workers in 2013 and 2020. Table 2 shows that the burnout scores were statistically significantly higher in dimensions of emotional exhaustion $(\mathrm{p}=0.001)$ and personal accomplishment $(\mathrm{p}=0.001)$. During the COVID-19 pandemic, healthcare workers in Slovenian nursing homes in rural areas suffered more from emotional 
exhaustion and lack of personal accomplishment than in spring 2013.

Table 2. Burnout dimensions' scores in $2013(n=556)$ and $2020(n=781)$

\begin{tabular}{lccc}
\hline Burnout dimensions & $2013 \overline{\mathrm{X}}(\mathrm{SD})$ & $2020 \overline{\mathrm{X}}(\mathrm{SD})$ & $\mathrm{p}$-value \\
\hline Emotional exhaustion & $21.9(9.2)$ & $24.8(10.8)$ & 0.001 \\
\hline Depersonalization & $8.1(4.3)$ & $8.2(4.9)$ & 0.467 \\
\hline Personal accomplishment & $42.7(9.1)$ & $48.7(11.8)$ & 0.001 \\
\hline
\end{tabular}

Note: Mann-Whitney U test

The results of the comparison of age, gender, position and burnout dimensions in 2013 and 2020 presented in Table 3 show that there were no statistically significant differences between the majority of the groups studied. However, the results show statistically significant differences in positions and emotional exhaustion $(\mathrm{p}=0.05) \mathrm{s}$ well as depersonalization $(\mathrm{p}=0.01)$ in 2013 . The highest emotional exhaustion and depersonalisation in 2013 were experienced by nurses, and the lowest level by nursing assistants.

Table 4 shows job satisfaction scores of healthcare workers in rs 2013 and 2020. It was identified that the scores were significantly lower in all three dimensions: intrinsic satisfaction $(p=0.011)$, extrinsic satisfaction $(p=0.004)$ and overall satisfaction $(\mathrm{p}=0.028)$. During the COVID-19 pandemic, healthcare workers in nursing homes in Slovenia were less satisfied with their work than in spring 2013.

Table 4. Job satisfaction dimensions' scores in $2013(n=556)$ and 2020 $(n=781)$

\begin{tabular}{lccc}
\hline Burnout dimensions & $2013 \overline{\mathrm{X}}(\mathrm{SD})$ & $2020 \overline{\mathrm{X}}(\mathrm{SD})$ & $\mathrm{p}$-value \\
\hline Intrinsic satisfaction & $36.4(8.9)$ & $31.7(9.9)$ & 0.011 \\
\hline Extrinsic satisfaction & $39.2(9.1)$ & $30.2(9.8)$ & 0.004 \\
\hline Overall satisfaction & $75.6(12.1)$ & $61.9(13.6)$ & 0.028 \\
\hline
\end{tabular}

Note: Mann-Whitney U test

Results of the comparison of age, gender, position and job satisfaction in 2013 and 2020 show that there were no statistically significant differences between the studied groups (Tab. 5).

A linear regression model was made to identify the relationships between one dependent variable, i.e. the overall (intrinsic and extrinsic) job satisfaction in both analysed years and different independent variables, i.e. dimensions of burnout syndromes in specific years (2013 and 2020), based on association previously shown in the bivariate analysis. All regression results indicate negative correlations between overall satisfaction, emotional exhaustion and personal accomplishments in 2013 and 2020 (Tab. 6).

Table 3. Relationship of burnout dimensions and age, gender, position in $2013(n=556)$ and $2020(n=781)$

\begin{tabular}{|c|c|c|c|c|c|c|}
\hline & \multicolumn{3}{|c|}{$2013 \bar{X}(S D)$} & \multicolumn{3}{|c|}{$2020 \bar{X}(S D)$} \\
\hline & $\mathrm{EE}$ & DP & PA & $\mathrm{EE}$ & DP & PA \\
\hline Gender $(p)^{*}$ & 0.572 & 0.716 & 0.174 & 0.598 & 0.619 & 0.729 \\
\hline Male & $21.8(9.2)$ & $8.0(4.1)$ & $42.5(9.0)$ & $24.6(10.8)$ & $8.1(4.2)$ & $48.6(11.9)$ \\
\hline Female & $22.1(10.2)$ & $8.3(4.5)$ & $42.9(9.5)$ & $25.0(11.2)$ & $8.4(5.6)$ & $48.8(11.6)$ \\
\hline Age $(\rho ; p)^{* *}$ & $0.232 ; 0.776$ & $0.013 ; 0.117$ & $0.128 ; 0.577$ & $0.213 ; 0.867$ & $0.217 ; 0.727$ & $0.011 ; 0.667$ \\
\hline Secondary school or less & & $8.4(4.5)$ & $42.5(9.7)$ & $24.9(10.5)$ & $8.4(4.9)$ & 48.9 (11.9) \\
\hline Bachelor's degree & $\begin{array}{l}21.8(9.1) \\
224(99)\end{array}$ & $7.8(4.1)$ & $42.8(9.0)$ & $24.7(10.6)$ & $8.2(4.8)$ & $48.5(11.8)$ \\
\hline Master's degree & $22.4(9.9)$ & $8.2(4.6)$ & $42.9(9.4)$ & $24.8(10.9)$ & $8.0(5.0)$ & $48.7(11.7)$ \\
\hline Position $(p)^{* * *}$ & 0.005 & 0.001 & 0.174 & 0.0761 & 0.089 & 0.381 \\
\hline Nurse & $22.2(10.2)$ & $8.7(4.8)$ & $42.6(9.2)$ & $24.6(11.2)$ & $8.5(5.0)$ & $48.8(11.9)$ \\
\hline Nursing assistant & $21.5(9.6)$ & $7.6(4.9)$ & $43.0(9.3)$ & $24.9(10.9)$ & $8.0(4.8)$ & $48.5(12.1)$ \\
\hline Nurse aide & $22.0(9.1)$ & $8.0(4.2)$ & $42.5(9.1)$ & $25.0(10.4)$ & $7.9(4.9)$ & $48.9(11.1)$ \\
\hline
\end{tabular}

Note: burnout dimension: EE - emotional exhaustion; DP - Depersonalization; PA - personal accomplishment.

* Mann-Whitney U Test; ** Spearman's $p ;{ }^{* * *}$ Kruskal-Wallis U test

Table 5. Relationship of dimension of job satisfaction and age, gender, position in $2013(n=556)$ and $2020(n=781)$

\begin{tabular}{|c|c|c|c|c|c|c|}
\hline & \multicolumn{3}{|c|}{$2013 \bar{X}(S D)$} & \multicolumn{3}{|c|}{$2020 \bar{X}(S D)$} \\
\hline & Intrinsic & Extrinsic & Overall & Intrinsic & Extrinsic & Overall \\
\hline Gender (p)* & 0.552 & 0.3741 & 0.112 & 0.398 & 0.217 & 0.223 \\
\hline Male & $38.1(9.9)$ & $39.5(9.8)$ & $75.7(12.5)$ & $31.9(10.1)$ & $31.2(10.8)$ & $60.8(13.6)$ \\
\hline Female & $35.2(7.9)$ & $39.1(9.7)$ & $75.4(11.7)$ & $31.5(9.7)$ & $29.2(8.8)$ & $62.9(13.6)$ \\
\hline Age $(\rho ; p)^{* *}$ & $0.243 ; 0.527$ & $0.022 ; 0.211$ & $0.223 ; 0.478$ & $0.241 ; 0.771$ & $0.119 ; 0.225$ & $0.001 ; 0.191$ \\
\hline Secondary school or less & $35.3(7.9)$ & $39.8(9.9)$ & $74.7(12.1)$ & $32.5(7.9)$ & $32.4(7.8)$ & $63.5(11.6)$ \\
\hline Bachelor's degree & $38.8(11.9)$ & $38.6(9.6)$ & $76.5(12.1)$ & $30.9(9.9)$ & $30.2(11.8)$ & $60.1(14.6)$ \\
\hline Master's degree & $34.3(10.2)$ & $39.2(10.9)$ & $75.6(12.1)$ & $31.7(11.7)$ & $28.0(9.8)$ & $62.1(15.6)$ \\
\hline Position (p) *** & 0.311 & 0.111 & 0.077 & 0.142 & 0.192 & 0.218 \\
\hline Nurse & $38.6(9.8)$ & $38.8(9.1)$ & $73.6(12.1)$ & $30.7(9.9)$ & $27.9(9.8)$ & $60.9(13.6)$ \\
\hline Nursing assistant & $34.4(9.1)$ & $39.7(9.1)$ & $76.3(12.1)$ & $32.9(9.9)$ & $31.1(9.8)$ & $61.8(13.6)$ \\
\hline Nurse aide & $35.5(11.2)$ & $39.3(9.1)$ & $77.2(12.1)$ & 31.5 (9.9) & $31.4(9.8)$ & $62.9(13.6)$ \\
\hline
\end{tabular}

Note: burnout dimension: E - emotional exhaustion; D - Depersonalization; PA - personal accomplishmen. * Mann-Whitney U test; ** Spearman's $\rho$; ${ }^{* * *}$ Kruskal-Wallis $U$ test. 
Table 6 Regression models for overall satisfaction in 2013 and 2020 $(n=1.337)$

\begin{tabular}{lcccc}
\hline & \multicolumn{5}{c}{ Overall Satisfaction } \\
\hline Emotional exhaustion 2013 & B & SE & $b$ & p-value \\
\hline Personal accomplishment 2013 & -1.036 & 0.331 & -0.211 & 0.031 \\
\hline Emotional exhaustion 2020 & -1.051 & 0.271 & -0.439 & 0.041 \\
\hline Personal accomplishment 2020 & -1.029 & 0.181 & -0.421 & 0.021 \\
\hline Multiple R & -1.025 & 0.329 & -0.279 & 0.011 \\
\hline
\end{tabular}

Qualitative analysis - in-depth interviews 2020. Results of the in-depth interview analysis showed a relatively homogeneous experience of burnout and job satisfaction by respondents. The first common characteristic of the respondents' statements was that they all clearly expressed burnout syndromes, regardless of gender, age and position. Although the criteria for participation in the interviews did not include the burnout syndrome, all respondents clearly emphasized their different symptoms: physical (chronic fatigue, extreme exhaustion, reduced energy, and sleep disturbances), emotional (frustration, irritability, anger and fear), cognitive (mental fatigue, difficulty in making decisions) and behavioural (negativism, emotional outbursts, cynicism, rudeness). Another common characteristic was the homogeneous statement of the respondents that before the COVID-19 pandemic they showed signs of lower burnout levels, and that the situation during the COVID-19 pandemic dramatically worsened their burnout syndromes. This id not apply to some signs of depersonalization, as respondents reported more negativism and cynicism and less interpersonal distance, as well as more emotional or cognitive involvement with their work than before the COVID-19 pandemic: they were more involved with co-workers and more engaged in working with residents/patients. The third characteristic was an established negative cause-and-effect relationship between job satisfaction and burnout: job dissatisfaction caused higher burnout. The fourth common characteristic was that respondents indicated a more or less homogeneous combination of certain elements of job satisfaction (responsibility, physical condition, knowledge and skills, timetable, management, recognition and salary). They had different views only on work colleagues. The fifth common characteristic was that the elements of the respondents' job satisfaction were justified both by the direct work environment, and in a broader sense, i.e. with theSstate and its institutions or politicians, who directly affected their working conditions and recognition in society.

All respondents stated that the feeling of burnout increased radically during the COVID-19 pandemics due to the enormous increase in responsibility, as they were responsible for their own safety, the safety of co-workers, as well as the safety of the residents'/patients'. As the measure of social distance was applied, they had to reassure and otherwise encourage patients who were under pressure due to the complete ban on visits to homes, the ban on leaving the premises, and limited social contacts. They also had to communicate with relatives who wanted to obtain additional information about the residents because of the ban on visit. Three respondents added that they also lost a lot of energy by replacing relatives when patients were dying. A typical example was Nursing Assistant 1:
Yes, I admit ... I'm over the edge now ... I need a rest, but I can't leave now. Not know ... I'm very worried... I've hardly slept for three weeks, I'm nervous and I'm crazy about every little thing because I'm afraid that I'll get infected or I'll infect my loved ones at home ... There's too much of everything ... I'd hardly done anything in a hurry before coronavirus ... Now it's crazy ... and now we need to tell them the same thing a hundred times ... that they cannot go to the dining room and so on ... And yesterday I was totally crazy ... I cried ... It was too much ... It was dying ...You know... I couldn't let a man die alone... It took away that little strength I had left.

Directly connected with the increased responsibility, the respondents also reported a lack of knowledge and skills in the prevention of infection, as well as poor management by the directors of nursing homes, State institutions, and politicians, who illegally required nursing homes to treat patients with COVID-19, even though they were not registered, and without receiving adequate protective equipment. Nurse 1:

Not just me ... we are all without energy and totally exhausted ... almost suffering from a nervous breakdown because we are doing things about which we have no knowledge and no legal cover whatsoever. ... There is a basic problem: we have become hospitals for our residents, even though we are only supposed to replace a home for older people ... So now we have to improvise because we don't have the knowledge, people, premises, equipmen ... Our director has a hard time managing ... several times a day we get a new directive from her. And basic protective equipment is missing. Can you imagine, we didn't even have enough masks the first days! It is not her fault, but the Ministry that issued such a decree. We and all the patients are the victims of politicians. I barely worked and lived before the coronavirus, but now I'm a zombie.

Also, all the respondents justified their 'abnormality' with a 12-hour working day, without the usual breaks, an imbalance between work and leisure, and an impaired physical condition. Four respondents emphasized the fact that they also had to live separately from their families to avoid infecting the family members. Nurse Aide 2:

We, who work in the red zone with the sick ones, have nowhere to go, no coffee, no smoke break. Have you ever worked with this equipment on? This is not normal. You start to sweat, your glasses are dewy, everything hurts, you are completely exhausted. ... You can't regenerate because you can't go home.

The respondents added that their work and the lives of the elderly people were not recognized by the State/politicians. A statement by Nurse 1 was typical: 'To be hones, the politicians have sacrificed us. We will totally burnout and the elderly will die due to COVID-19. We are worth nothing to them!' They all attributed their burnout to the low salary and to the crisis allowance that was wrongly granted, as stated by Nurse Assistant.: 'It's simply not fair that everybody received the allowance; also someone who doesn't work or someone who is not working under the same conditions as I am! And 
that would be funny if it didn't hurt! And it hurts a lot! I'm so angry!'

Respondents' interpretations only differed in the element of satisfaction with work colleagues. Most respondents indicated that working relations between employees improved compared to the situation before the COVID-19 pandemic, because employees had to cooperate more and had a 'common external enemy', i.e. COVID-19 and politicians. 'The only thing that is really good in this unbearable situation, and even makes me think not to leave immediately, are better relationships between us. ... Why? Because we depend on each other and help each other, and because our enemy was external ... Coronavirus and incapable and corrupt politicians', typically claimed Nurse 2 . In certain nursing homes, relations did not improve during the crisis. Three respondents said that satisfaction with work colleagues deteriorated greatly because 'the extreme situation exacerbated personal inadequacies', according to Nurse Aide 3 , 'because others came to us who we did not know and did not adjust", and 'because some employees took sick leave and abandoned us,' remarked Nursing Assistant 3.

\section{DISCUSSION}

The quantitative and qualitative approach that was adopte, proved to be useful, since it enabled results to be obtained that could be generalised and also allow an in-depth insight into the respondents' views on burnout and job satisfaction, and reveal information the survey could not otherwise have obtained. In addition, the in-depth interviews allowed verification of the validity of the survey results, thus leading to their explanation.

The perception of burnout and job satisfaction of Slovenian healthcare workers in nursing homes in rural areas in 2013 and 2020 was chosen for the study because they work in a weakly developed long-care system, typical for Central and Eastern European countries [22], which has rarely been the subject of research. At the same time, the researchers wanted to discover whether the relationship between burnout and job satisfaction was influenced by the COVID-19 pandemic, which disproportionately affected nursing homes [11].

In general, the results show that already in spring 2013, Slovenian nursing homes healthcare workers in rural areas suffered badly from burnout syndromes (emotional exhaustion, personalisation and personal accomplishment), regardless of age and gender. In 2013, Statistically significant differences were identified only by the position and emotional exhaustion/depersonalisation. The highest emotional exhaustion and depersonalisation were experienced by nurses, the lowest level by nursing assistants. This is in line with the previous study arguing that nursing is widely considered to be one of the most stressful professions, associated with a high degree of burnout [1], and that socio-demographic variables had no significant effect on burnout dimensions of nursing home healthcare workers $[1,15]$.

During the COVID-19 pandemic, respondents, regardless of age, gender and position, experienced burnout syndromes. This can be explained by the results of in-depth interviews as the respondents predominantly argued that the situation in nursing homes was significantly worsened for all healthcare workers during the COVID-19 pandemic, and that their perception or feeling of burnout syndromes applied to all the employees in their nursing home, and even more generally to Slovenian nursing homes.

The results also show that respondents experienced emotional exhaustion and lack of personal accomplishment even more during the COVID-19 pandemic; however, their perception of depersonalisation was statistically no different from that in 2020. This can be explained by the results of the in-depth interviews, as respondents reported less interpersonal distance and more emotional or cognitive involvement with work during the COVID-19 pandemic. This is in line with the study demonstrating that in times of crisis like the COVID-19 pandemic, the personal engagement that reduces depersonalization is essential to managing the work situation [22].

The results of the online survey and in-depth interviews also show that respondents experienced lower levels of burnout already before the COVID-19 pandemi, due to overwork, constant concern, high responsibility and pressure, low salary, lack of awards and recognitions [3]. The COVID-19 pandemic drastically exacerbated the already existing burnout syndromes by job dissatisfaction with the elements connected with the direct working environment (e.g. timetable, management and salary) and the work of state institutions and politicians, which directly affected their work (management, crisis allowance and recognition). The respondents were especially dissatisfied with the inadequate provision of protective equipment and the requirement to treat elderly residents who were infected with COVID-19 in nursing homes and not in hospitals by the Slovenian Ministry of Healt, and the lack of recognition by the Slovenian government politicians of the importance of the work in nursing homes and the lives of older people. The study also revealed that the job satisfaction of healthcare workers during the COVID-19 pandemic was not only related with job satisfaction in nursing homes, but also with the work of State institutions and politicians who directly affected their working conditions, and their recognition by society.

Negative correlation in regression analysis was identified between overall (intrinsic and extrinsic) job satisfaction in 2020 and emotional exhaustions and personal accomplishments in 2013 and 2020. Personalisation was not associated with the overall satisfaction of the healthcare workers. This means that healthcare workers in nursing homes who are more satisfied with the job, experience less emotional exhaustion and personal accomplishments, and vice versa. This is in line with the findings of a Turkish study on burnout and job satisfaction which shows that job satisfaction is not related to depersonalisation [20]; however, in contrast to the finding of Fontova-Almato et al. [21, who measured the relationship between job satisfaction and the burnout levels of Spanish emergency department professionals, found an inverse relationship between depersonalisation and overall job satisfaction. This can be explained by the results of bivariate analysis and in-depth interviews, namely, that the majority of job satisfaction variables had significantly declined by 2020, whereas depersonalization had remained more or less the same due to the greater engagement and connectivity of healthcare workers, as was shown by the results of the in-depth interviews. This means that the pandemic crisis has activated specific reactions in nursing homes healthcare workers.

The current study has contributed to the deepening of scientific knowledge of the relationship between job satisfaction and burnout by demonstrating that job 
satisfaction is a predictor of burnout. Results of the in-depth interviews confirm those studies showing that job satisfaction causes burnout syndromes by healthcare workers [21], and not vice versa [23].

The hypothesis that job satisfaction and burnout levels of the healthcare professionals working in Slovenian nursing homes during the COVID-19 pandemic are related, has mostly been confirmed, as negative correlation exists between overall job satisfaction, emotional exhaustion, and personal accomplishmen However, no relationship was observed between job satisfaction and depersonalisation.

The current study has three main limitations. 1) The influence of the COVID-19 pandemic on job satisfaction and burnout levels has not been directly measured, but only by professional burnout and job satisfaction during the COVID-19 pandemic. 2) In the first research step in 2013, in-depth interviews were not conducted to obtain an in-depth insight into the respondents' views on burnout and job satisfaction. 3) The use of sampling methods in the qualitative part of the research; perhaps the use of other sampling methods would provide additional or a better insight into the burnout experiences of health professionals during the pandemic COVID - 19 .

The study results expose a need to reform long-term care in Slovenia and other countries in the region to prevent healthcare workers' burnout. Systemic changes are needed. Nursing homes as social welfare institutions must perform their primary function and should not be a substitute for (palliative) hospitals. The introduction of adequate normative regulation of healthcare workers to reducethea shortage of healthcare workers are needed. Thus, the study shows that healthcare professionals working in Slovenian nursing homes in rural areas are overburdened. In addition, nursing homes need to begin developing a process for evaluation of the psychosocial and medical risk factors contributing to burnout, and to financial losses due to sick leaves, and the threat to patients' safety and the quality of healthcare [3]. With regard to the crisis caused by the COVID-19 pandemic, nursing homes should prepare a crisis management plan for such situations, in particular, a crisis plan for a possible second wave, and provide healthcare workers with training for dealing with such situations.

\section{CONCLUSIONS}

Job satisfaction and professional burnout are factors that influence the health of professionals, have an economic impact on the health sector and influence the quality of healthcare in nursing homes. This research enables us to see how the measures applied during the pandemic COVID-19 have affected the satisfaction and burnout of healthcare professionals.

In Slovenia, an Eastern European country with a weakly developed long-term care, the COVID-19 pandemic significantly exacerbated already existing burnout syndromes. The respondents experienced emotional exhaustion and lack of personal accomplishment even more during the COVID-19 pandemic; however, their perception of depersonalisation was statistically no different in 2020 from those in 2013 due to personal engagement.

Due to the consequences of burnout among health care professionals in nursing homes, this study encourages policy makers, nursing home administrations and healthcare managers to prevent and minimise burnout among healthcare professionals.

\section{REFERENCES}

1. Harrad R, Sulla F. Factors associated with and impact of burnout in nursing and residential home care workers for the elderly. Acta Biomed. 2018; 89(7): 60-69. https://doi.org/10.23750/abm.v89i7-S.7830

2. Drennan J, Lafferty A, Treacy MP, Fealy G, Phelan A, LyonsI, Hall P. Older People in Residential Care Settings: Results from a National Survey of Staff-Resident Interactions and Conflicts. NCPOP: University College Dublin, 2012. Available at http://www.rte.ie/documents/news/ elderlyreport.pdf. Accessed 6 June 2020.

3. Leskovic L, Vukovič G, Leskovar R, Goriup J. Some Aspects of Burnout in Nursing Homes. A Tech Dub. 2016; 6(2): 47-62.

4. Neuberg $M$, et al. Is the burnout syndrome associated with elder mistreatment in nursing homes: a cross-sectional study among nurses. Arh Hig Rada Toksikol. 2017; 68: 190-197. https://doi.org/10.1515/ aiht-2017-68-2982.

5. White EM, Aiken LH, McHugh MD. Registered Nurse Burnout, Job Dissatisfaction, and Missed Care in Nursing Homes. J Am Geriatr Soc. 2019; 67: 2065-2071. https://doi.org/10.1111/jgs.16051

6. Adams JG, Walls RM. Supporting the Health Care Workforce During the COVID-19 Global Epidemic. JAMA 2020; 323(15): 1439-1440. https://doi.org/10.1001/jama.2020.3972

7. Choi KR, Skrine Jeffers K, Logsdon MC. Nursing and the Novel Coronavirus: Risks and Responsibilities in a Global Outbreak. J Adv Nurs. 2020; 23: 1-2. https://doi.org/10.1111/jan.14369

8. McMichael TM, Currie DW, Clark S, Pogosjan A, Kay M, Schwartz NG, et al. Public Health-Seattle and King County, Evergreen Health, and CDC COVID-19 Investigation Team. Epidemiology of Covid-19 in a Long-Term Care Facility in King County, Washington. N Engl J Med. 2020; 382(21): 2005-2011. https://doi.org/10.1056/NEJMoa2005412

9. Wang H, Li T, Barbarino P, Gauthier S, Brodaty H, Molinuevo HL, Xie H, Sun, Yu E, Tang Y, Weidner W, Yu X. Dementia Care During COVID-19. Lancet. 2020; 395(10231): 1190-1191. https://doi. org/10.1016/S0140-6736(20)30755-8

10. Ali SA, Baloch M, Ahmed N, Ali AA, Iqbal A. The Outbreak of Coronavirus Disease 2019 (COVID-19)-An Emerging Global Health Threat. J Infect Public Health. 2020; 13(4): 644-646. https://doi. org/10.1016/j.jiph.2020.02.033

11. Fallon A, Dukelow T, Kennelly SP, O’Neill D. COVID-19 in Nursing Homes. QJM. 2020 Apr 20: hcaa136. Published online 2020 Apr 20. https://doi.org/doi: 10.1093/qjmed/hcaa136

12. Maslach C, Jackson SE. The measurement of experienced burnout. J Occupat Behav. 1981; 2: 99-113.

13. Awa WL, Plaumann M, Walter U. Burnout prevention: a review of intervention programs. Patient Educ Couns. 2016; 78(2): 184-190. https://doi.org/10.1016/j.pec.2009.04.008.

14. World Health Organization https://www.who.int/mental_health/ evidence/burn-out/en/ Accessed 6 June 2020.

15. Cooper AL, Carleton HL, Chamberlain ST, Cummings GG. Burnout in the nursing home health care aide: a systematic review. Burnout Res. 2016; 3: 76-87. https://doi.org/10.1016/j.burn.2016.06.003.

16. Alarcon, GM. A meta-analysis of burnout with job demands, resources, and attitudes. J Vocat Behav. 2016; 79: 549-562. https://doi.org/10.1016/j. jvb.2011.03.007

17. Dugguh SI, Ayaga D. Job satisfaction theories: Traceability to employee performance in organizations. IOSR J Bus Manag. 2014; 16: 11-18.

18. Herzberg F, Mausner B. The Motivation to Work. Transaction Publishers, New Brunswick, USA, 1993.

19. Vassbø TK, Kirkevold M, Edvardsson D, Sjögren K, Lood Q, Sandman PO, Bergland A. Associations between job satisfaction, personcentredness, and ethically difficult situations in nursing homes-A cross-sectional study. J Adv Nurs. 2019; 75: 979-988. https://doi. org/10.1111/jan.14011

20. Tarcan M, Hikmet N, Schooley B, Top M, Tarcan GY. An analysis of the relationship between burnout, socio-demographic and workplace factors and job satisfaction among emergency department health professionals. Appl Nurs Res. 2017; 34: 40-47. https://doi.org/10.1016/j. apnr.2017.02.011

21. Fontova-Almató A, Suñer-Soler R, Salleras-Duran L, Bertran-Noguer C, Congost-Devesa L, Ferrer-Padrosa M, Juvinyà-Canal D. Evolution 
Ljiljana Leskovic, Karmen Erjavec, Robert Leskovar, Goran Vukovič. Burnout and job satisfaction of healthcare workers in Slovenian nursing homes in rural areas...

of Job Satisfaction and Burnout Levels of Emergency Department Professionals during a Period of Economic Recession. Int J Environ Res Public Health. 2020; 17: 921-33. https://doi.org/10.3390/ijerph17030921 22. Employee job satisfaction and engagement: Revitalizing a Changing Workforce. https://www.shrm.org/hr-today/trends-and-forecasting/ research-and-surveys/Documents/2016-Employee-Job-Satisfactionand-Engagement-Report.pdf. Accessed 19 June 2020.

23. Smolej Jež S, Nagode MA. Dramatic divide between social home care and institutional care. Good Quality Old Age. 2017; 20: 3-15.
24. Leskovic L. Influence of work and organizational factors on the development of burnout syndrome in social welfare institutions in the Republic of Slovenia. Doctoral dissertation. Kranj University of Maribor, 2014.

25. Maslach C. Schaufeli WB, Leiter MP. Job burnout. Annu Rev Psychol. 2012; 52: 397-422.

26. Boyce C, Palena N. Conducting in-depth interviews. http://www2. pathfinder.org/site/DocServer/m_e_tool_series_indepth_interviews. pdf. Accessed 9 June 2020. 